\title{
Microstructural Characterization of Air Electrode Architectures in Lithium-Oxygen Batteries
}

\author{
Jianguo Wen ${ }^{1}$, Jun Lu ${ }^{2}$, D.J. Miller ${ }^{1}$, Xiangyi Luo ${ }^{2}$, Hsien-Hau Wang ${ }^{3}$, Kah Chun Lau ${ }^{3}$, Eric Tyo ${ }^{3}$, \\ Stefan Vajda ${ }^{3}$, Larry A. Curtiss ${ }^{3} \&$ Khalil Amine $^{2}$ \\ ${ }^{1}$ Electron Microscopy Center - Center for Nanoscale Materials, Argonne National Laboratory, USA \\ ${ }^{2}$ Chemical Sciences and Engineering Division, Argonne National Laboratory, USA \\ ${ }^{3}$ Materials Science Division, Argonne National Laboratory, USA
}

The aprotic Lithium-Oxygen $\left(\mathrm{Li}-\mathrm{O}_{2}\right)$ batteries, consisting of lithium metal and porous air electrode separated by electrolyte, have the potential needed for long-range electric vehicles. The architectures of air electrodes are found to be of paramount importance to achieve good electronic and ionic conductivity, fast oxygen diffusion, and stable integrity for high-performance $\mathrm{Li}_{-} \mathrm{O}_{2}$ batteries [1].

In this work, we first characterized an air electrode showing a dramatic reduction in charge overpotential [1]. We found that the nanostructured cathode architecture with an $\mathrm{Al}_{2} \mathrm{O}_{3}$ coating and $\mathrm{Pd}$ nanoparticles led to a nanocrystalline lithium peroxide $\left(\mathrm{Li}_{2} \mathrm{O}_{2}\right)$ discharge product that contributes to the low overpotential. As shown in Fig. 1a, the pristine carbon (super P) surface has almost no amorphous phase. The carbon surface was partially coated with 3 cycles of $\mathrm{Al}_{2} \mathrm{O}_{3}$ (Fig. 1b) by atomic layer deposition to passivate carbon defect sites. The protective $\mathrm{Al}_{2} \mathrm{O}_{3}$ coating on the air cathode prevents electrolyte decomposition on carbon defect sites, which can increase the charge potential. Fig.1c shows the Pd nanoparticles $(2-6 \mathrm{~nm})$ are often directly attached to the carbon support. The architecture of cathode promotes growth of a nanocrystalline form of discharged product $\mathrm{Li}_{2} \mathrm{O}_{2}$ as shown in Fig. 1d. Density functional theory calculations show that amorphous $\mathrm{Li}_{2} \mathrm{O}_{2}$ may have a metal-like density of states, in contrast to the poor electronic conductivity of crystalline $\mathrm{Li}_{2} \mathrm{O}_{2}$ [1]. The amorphous $\mathrm{Li}_{2} \mathrm{O}_{2}$ in the grain boundaries improves electronic transport properties that are needed to lower the charge potential. Fig. 1e shows a dramatic reduction in overpotential of $\sim 0.2 \mathrm{~V}$ during charge using the nanostructured cathode architecture.

To further understand the effect of metal nanoparticle on the growth of $\mathrm{Li}_{2} \mathrm{O}_{2}$, subnanometer silver clusters of defined size and number of atoms were deposited on passivated carbon [2]. Fig. 2a shows a TEM image of a 15 atom Ag cluster (Ag15) on an $\mathrm{Al}_{2} \mathrm{O}_{3}$ coated carbon particle. In most cases, discrete Ag15 clusters are observed. Occasionally, agglomeration of the Ag15 clusters (circled in Fig. 2a) is observed. Fig. 2b shows the atomic structure in an Ag15 cluster from a video (1 frame per second). The atomic arrangement of the clusters changes quickly under the electron beam, so very low-dose imaging techniques were required to obtain these images. SEM observation indicates that dramatically different morphologies of the discharged product $\mathrm{Li}_{2} \mathrm{O}_{2}$ is dependent on the size of the Ag clusters [3]. The $\mathrm{Li}_{2} \mathrm{O}_{2}$ product using Ag3 clusters as a catalyst is film-like. In contrast, the discharge product using Ag9 clusters is largely toroid-like with rough surfaces, while $\mathrm{Li}_{2} \mathrm{O}_{2}$ toroids obtained using the Ag15-based cathode have smooth surfaces. The discharge capacity $(\sim 3500$ $\mathrm{mAhg}^{-1}$ ) for the first cycle of the cell with the Ag15-based cathode is much larger than that using the Ag3 and Ag9 clusters $\left(\sim 2400 \mathrm{mAhg}^{-1}\right)$. The results of this study indicate that precise control of subnanometer size of catalytic nanoparticles on air electrodes can be used as a means to improve the performance of lithium-oxygen cells $[3,4]$. 


\section{References:}

[1] Jun Lu, et al, Nature Communications, DOI:10.1038/ncomms3383 (2013).

[2] S. Vajda, et al. Nature Materials, 8, 213-216 (2009).

[3] Jun Lu, et al, Nature Communications, DOI:10.1038/ncomms5895 (2014).

[4] Research at the Electron Microscopy Center - Center for Nanoscale Materials at Argonne National Laboratory is supported by the U.S. Department of Energy, Office of Science, Office of Basic Energy Sciences, under Contract No. DE-AC02-06CH11357.
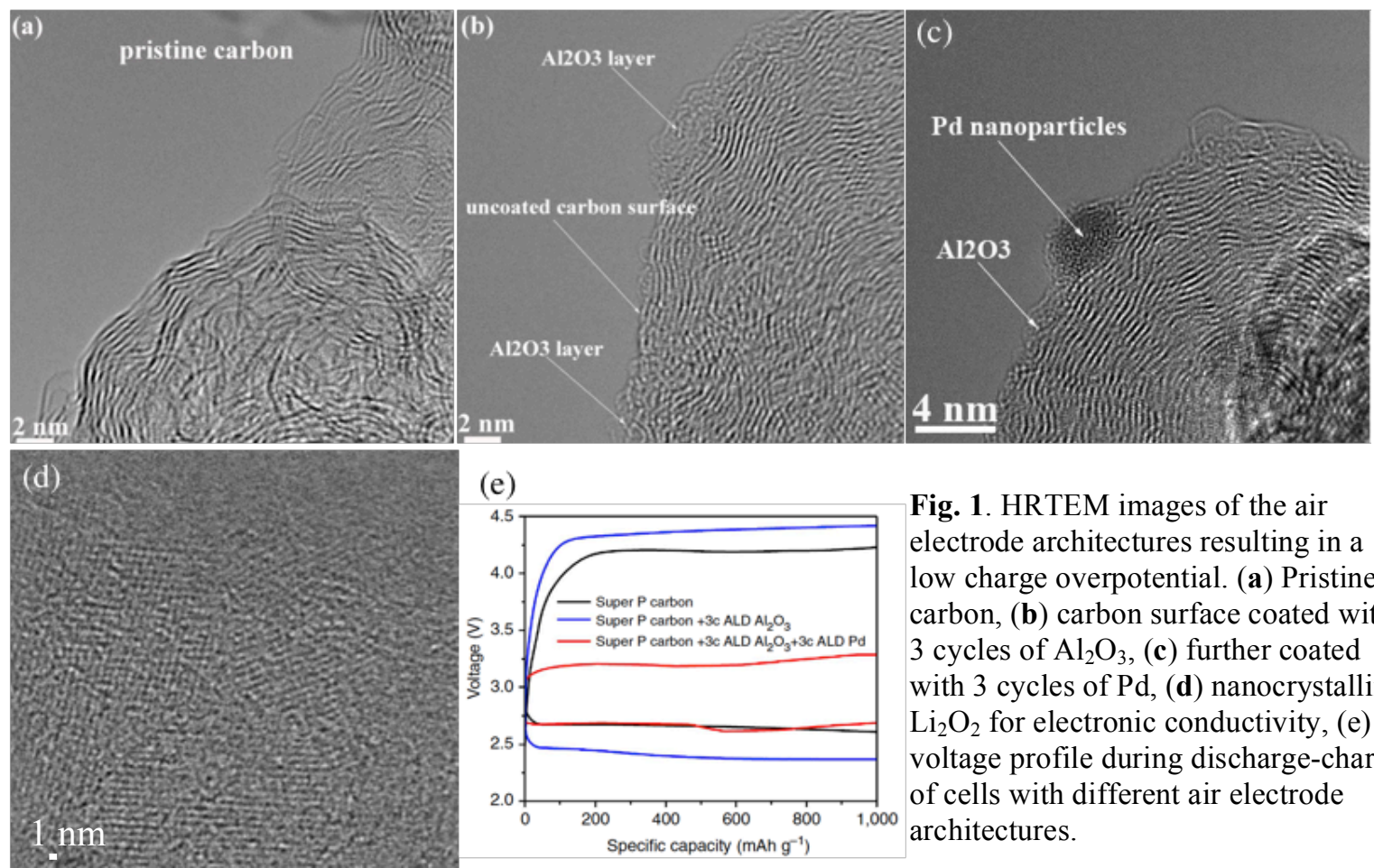

Fig. 1. HRTEM images of the air electrode architectures resulting in a low charge overpotential. (a) Pristine carbon, (b) carbon surface coated with 3 cycles of $\mathrm{Al}_{2} \mathrm{O}_{3}$, (c) further coated with 3 cycles of $\mathrm{Pd}$, (d) nanocrystalline $\mathrm{Li}_{2} \mathrm{O}_{2}$ for electronic conductivity, (e) voltage profile during discharge-charge of cells with different air electrode architectures.

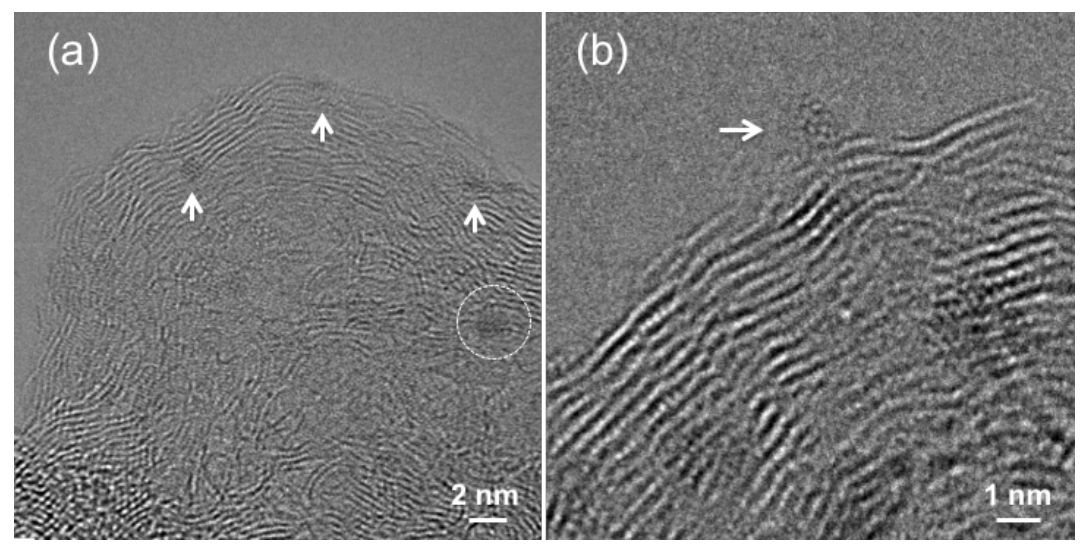

Fig. 2. HRTEM images of the air electrode architectures leading to the control of $\mathrm{Li}_{2} \mathrm{O}_{2}$ morphologies. (a) TEM image of $\mathrm{Ag} 15$ clusters (arrows) on an $\mathrm{Al}_{2} \mathrm{O}_{3}$ coated carbon particle. Occasionally, agglomeration of Ag15 clusters (circled) is observed. (b) HRTEM image of an Ag15 cluster on an $\mathrm{Al}_{2} \mathrm{O}_{3}$ coated carbon surface. 